\title{
Study on the Importance of Attention and Combativity in Competitions at J udoka athletes for 11-13 Years
}

\author{
Sava Mihai-Adrian ${ }^{1 *}$ \\ Panaitescu Ana-Maria² \\ 1“Vasile Alecsandri” University of Bacau, 157, Calea Mărășești, 600115, Romania \\ ${ }^{2}$ Secondary School no. 22, Bacău, General Gușă 3, 600234, Romania
}

Keywords: judo, attention, combativeness.

\begin{abstract}
Attention and combativeness are two factors which can influence the performance of the judoka. In order to demonstrate the importance of attention and combativeness in judo competitions, we made an observation protocol named "The importance of attention and combativeness in judo competitions" applied to a sample of 30 judokas aged 11-13 years old. By developing attention, judo athletes are able to mobilize timely and efficient forces to conduct rational behaviour. He has a higher speed of reaction rate, is focused more on the mat, the processes of perception arising faster, are more clear and active, his ability of observation increases as well the ability to seize the most unusual and difficult situations while fighting. Judokas' control on their actions is rational and very accurate, and movements have perfect coordination and are more precise. He has self-confidence (Angus, 2006). He is able to perform a self-critical analyse after each match and draw conclusions for the next matches.
\end{abstract}

\section{Introduction}

Judo philosophy is reflected in the motto "Jita Kyoei" that "everything as a unit." The value of tradition and philosophy of judo and the benefits that emerge from them are crucial. Judoka must learn to respect himself, his body, his coach (Gagea, 2007). Judo athletes should not be trained only physically, but in spirit, by their power of concentration, dedication. So, an important role in judo it is mental preparation (Hantău, 2005).

Combativeness is the tendency to fight with all their energy to achieve the purpose of overcoming the opponent, and other "barriers" (space, time, and gravity) or their previous performance (Verza, 2000). Combative attitude achieves active and constructive features, the individual using his intelligence and his behaviour doubled by courage, fighting spirit of sacrifice (Epuran, 2008). In judo, while being art and sport, the principles are clear and promotes individual with special physical and mental aspects, maximum discipline, stoicism, honesty, respect for self and

*E-mail: sava.adrian@ub.ro, tel.0741996105 
society (Bompa, 2009). So, combativeness in judo is essential for defining judo athlete. Sometimes combativeness is associated with aggression, but according to the principles of his mentor Jigoro Kano aggression has no place in judo (Deliu, 2008). However there are rare cases of aggressive behaviour, but are severely punished, up to eliminating the athlete from sport life (Pop, 2007).

\section{Material and methods}

The aim of this study was to identify and objective assessment of the general level of attention and combativeness, to optimize the process of psychological training to underpin the implementation of instructional strategies.

Considering the scope of our research and our expectations we formulated the following hypotheses:

1. Attention, combativeness and speed of response are components of mental capacity that favour / limits athletic performance in judo.

2. In the preparation of judo player distributive concentration and attention, combativeness and speed of response are the independent variables of mental capacity.

In the present study we used methods such as the bibliographic study in order to see how this subject is seen on the scientifically literature, the method of direct pedagogical observation and the statistical mathematic method to interpret and present the results. Direct pedagogical observation method applied in our work was focused on careful and systematic recording of reactions and behaviours of judo athletes 11-13 years of motor and psychomotor skills, psychological skills, aiming at the same time the behavioural and temperamental characteristics of the adolescents in the process of judo training.

The subjects of the study were 30 judoka from Club Royal Bacau.

The study was conducted by using a protocol named "The importance of attention and combativeness in judo competitions", applied on the target group. The protocol is presented as follows in Tabel 1.

In achieving this protocol we considered the different stages of the competition since its entry into the competition room and the mattress, and the gradual transition through different stages of a fight (taking the grips, entry in judo technics, fixation, luxation, completion actions). Each phase was observed from the point of view of our research and observation of certain components of attention (distributive attention, focus, the reaction rate) and combativeness involved in these processes.

Each item was measured on a scale from 1 to 5 where the minimum value 1 to 5 - the maximum, and for some items 1 to 4,1 being the minimum value and 4 the maximum. 
Table 1. Protocol of observation "Importance of attention and combativeness in judo competitions"

\section{The importance of attention and combativeness in judo competitions}

1. Focussing the attention before competition
Maxim(5)
Height(4) Medium(3)
Sufficient(2)
Insufficient(1)

2. Capacity to eliminate factors of attention distraction
V. $\operatorname{good}(5)$
Good(4) Medium(3)
$\operatorname{Low}(2)$
V. low(1)

3. Psychological state of the athlete before competition
V. $\operatorname{calm}(4)$
Calm(3)
Agitated(2)
Nervous(1)

4. Taking the appropriate grip when entering in a technique
V. $\operatorname{good}(5)$
Good(4)
Medium(3)
Low(2)
V. $\operatorname{low}(1)$

5. Adapting the athlete to the combat situation
V. $\operatorname{good}(5)$
Good(4) Medium(3)
$\operatorname{Low}(2)$
V. low(1)

6. Distribution of attention on various factors of a time of fight
V. $\operatorname{good}(5)$
Good(4) Medium(3)
$\operatorname{Low}(2)$
V. low(1)

7. Initiative

Permanent(5)

Often(4) Sometimes(3

Rarely (2)

Never(1)

8. Engaging in effort

Maxim(5) Height(4) Medium(3)

Sufficient(2)

Insufficient(1)

9. Attention of judoka to the opponent's tactic
V. $\operatorname{good}(5)$
Good(4) Medium(3)
$\operatorname{Low}(2)$
V. $\operatorname{low}(1)$

10. Finalisation of actions

$\begin{array}{llll}\text { Permanent(5) Often(4) Sometimes(3 } & \text { Rarely (2) } & \text { Never(1) }\end{array}$

11. Ending the fight by abandon
Never(5)
Rarely(4) Sometimes(3
Often(2)
Permanent(1)

12. The influence of external factors during the completion on judoka
Never(5)
Rarely(4) Sometimes(3
Often(2)
Permanent(1)

13.The capacity of psychological and physical recovery of judoka

$$
\text { Very high (4) }
$$

High(3)

Medium(2)

$\operatorname{Low}(1)$

14. Decisional responsibility Very high (4)

High(3)

Medium(2)

Low(1)

\section{Results and Discussions} table 2 .

Experimental data obtained after observation protocol are presented in the in the

According to centralized data presented in the table above, there are the following interpretations:

- Focussing the attention before competition - scores are included in the range of 2-5, the arithmetic mean is 3.16. The analysis of these values shows that the ability to focus attention in the moments before the competition is low for the subjects of the study.

- Capacity to eliminate factors of attention distraction - values are between 1 and 4 , the average value being 2.86. These values express that athletes have not special training on this issue, they cannot cope in the best possible way to external 
Sava M.A., Panaitescu A.M. / Gymnasium

factors such as public, electronic displays, stress, etc.

Table 2. Experimental data obtained following application of protocol od observation

\begin{tabular}{|c|c|c|c|c|c|c|c|c|c|c|c|c|c|c|}
\hline Nr. crt. & 01 & 02 & 03 & 04 & O5 & 06 & O7 & 08 & 09 & 010 & 011 & 012 & 013 & 014 \\
\hline S1 & 2 & 1 & 2 & 3 & 2 & 2 & 2 & 3 & 2 & 3 & 1 & 2 & 1 & 1 \\
\hline S2 & 3 & 3 & 2 & 3 & 3 & 3 & 2 & 3 & 3 & 2 & 2 & 2 & 2 & 2 \\
\hline S3 & 2 & 3 & 2 & 3 & 3 & 3 & 2 & 3 & 3 & 3 & 2 & 2 & 2 & 2 \\
\hline S4 & 4 & 3 & 3 & 3 & 4 & 4 & 3 & 4 & 3 & 4 & 3 & 3 & 2 & 3 \\
\hline S5 & 4 & 3 & 3 & 4 & 4 & 3 & 3 & 4 & 4 & 3 & 3 & 3 & 2 & 2 \\
\hline S6 & 2 & 2 & 3 & 2 & 3 & 3 & 3 & 2 & 3 & 3 & 3 & 2 & 2 & 2 \\
\hline S7 & 3 & 4 & 3 & 2 & 3 & 2 & 3 & 3 & 2 & 2 & 2 & 1 & 1 & 1 \\
\hline S8 & 3 & 4 & 3 & 4 & 4 & 3 & 2 & 3 & 3 & 3 & 4 & 3 & 3 & 2 \\
\hline S9 & 2 & 2 & 2 & 2 & 3 & 2 & 3 & 3 & 3 & 2 & 2 & 2 & 2 & 1 \\
\hline S10 & 3 & 3 & 2 & 3 & 2 & 3 & 3 & 3 & 2 & 2 & 3 & 3 & 2 & 2 \\
\hline S11 & 3 & 3 & 2 & 3 & 3 & 3 & 2 & 3 & 2 & 3 & 3 & 2 & 2 & 2 \\
\hline S12 & 4 & 3 & 3 & 3 & 4 & 4 & 3 & 4 & 3 & 3 & 3 & 4 & 3 & 3 \\
\hline S13 & 5 & 4 & 5 & 5 & 4 & 4 & 4 & 4 & 4 & 3 & 5 & 4 & 4 & 4 \\
\hline S14 & 2 & 3 & 4 & 3 & 3 & 3 & 2 & 3 & 3 & 3 & 3 & 2 & 3 & 3 \\
\hline S15 & 3 & 3 & 2 & 3 & 2 & 3 & 3 & 2 & 2 & 2 & 2 & 3 & 3 & 2 \\
\hline S16 & 3 & 3 & 2 & 4 & 3 & 3 & 3 & 3 & 2 & 3 & 2 & 2 & 3 & 2 \\
\hline S17 & 4 & 3 & 3 & 3 & 2 & 2 & 3 & 2 & 3 & 3 & 3 & 2 & 3 & 2 \\
\hline S18 & 2 & 2 & 2 & 2 & 3 & 2 & 2 & 3 & 4 & 3 & 3 & 3 & 2 & 2 \\
\hline S19 & 3 & 3 & 2 & 2 & 2 & 3 & 2 & 2 & 3 & 3 & 2 & 2 & 2 & 2 \\
\hline S20 & 3 & 3 & 2 & 3 & 3 & 2 & 3 & 3 & 3 & 3 & 3 & 2 & 2 & 3 \\
\hline S21 & 3 & 2 & 3 & 4 & 3 & 3 & 3 & 4 & 2 & 3 & 3 & 3 & 3 & 3 \\
\hline S22 & 3 & 1 & 2 & 2 & 3 & 1 & 2 & 3 & 3 & 2 & 3 & 3 & 2 & 2 \\
\hline S23 & 4 & 3 & 2 & 3 & 3 & 2 & 3 & 3 & 2 & 3 & 3 & 4 & 3 & 3 \\
\hline S24 & 4 & 3 & 2 & 3 & 3 & 3 & 4 & 4 & 3 & 3 & 3 & 3 & 2 & 3 \\
\hline S25 & 3 & 3 & 1 & 2 & 2 & 2 & 3 & 3 & 2 & 2 & 2 & 2 & 2 & 2 \\
\hline S26 & 5 & 4 & 4 & 3 & 3 & 3 & 2 & 2 & 3 & 3 & 3 & 3 & 3 & 3 \\
\hline S27 & 3 & 3 & 2 & 3 & 3 & 3 & 2 & 3 & 3 & 2 & 2 & 2 & 3 & 2 \\
\hline S28 & 4 & 3 & 3 & 4 & 3 & 4 & 3 & 3 & 4 & 3 & 3 & 3 & 3 & 3 \\
\hline S29 & 3 & 3 & 2 & 3 & 2 & 3 & 3 & 3 & 2 & 3 & 2 & 2 & 3 & 2 \\
\hline S30 & 3 & 3 & 1 & 2 & 1 & 2 & 2 & 2 & 2 & 2 & 2 & 1 & 2 & 1 \\
\hline Mean & 3.16 & 2.86 & 2.46 & 2.97 & 2.87 & 2.70 & 2.63 & 3.00 & 2.77 & 2.76 & 2.66 & 2.50 & 2.43 & 2.3 \\
\hline $\begin{array}{l}\text { Standard } \\
\text { deviation }\end{array}$ & 0.83 & 0.73 & 0.86 & 0.76 & 0.73 & 0.87 & 0.61 & 0.64 & 0.67 & 0.50 & 0.75 & 0.77 & 0.62 & 0.65 \\
\hline Vmax & 5 & 4 & 5 & 5 & 4 & 4 & 4 & 4 & 4 & 4 & 4 & 4 & 4 & 4 \\
\hline V.min & 2 & 1 & 1 & 2 & 1 & 1 & 2 & 2 & 2 & 2 & 1 & 1 & 1 & 1 \\
\hline
\end{tabular}

- Psychological state of the athlete before competition - the average value of the results is 2.46 minimum is 1 and the maximum of 5 . In this case, we observed that the general state of the athletes before the beginning of completion was not the most favourable for athletes, which are characterized by agitation or visible nervousness, few of them being characterized by calm and composedness. 
- Taking the appropriate grip when entering in a technique - the arithmetic mean is 2.97 also demonstrates poor attention.

- Adapting the athlete to the combat situation - results are between 1 and 4, the average values of 2, 87 also located in the poor results showing that athletes need some attention components to be developed so that the athlete grow their capacity of adaptation to fight situations.

- Distribution of attention on various factors of a time of fight - athletes registered a score of 2.70 which is a low value, when minimum value is 1 and a maximum of 4 .

- Initiative - there is a minimum of 2 and a maximum of 4 , the average being 2.63, also a low value, which highlights a low combativeness in battle, distrust in their own forces, a low reaction speed.

- Engaging in effort - the minimum value was 2, and the maximum value of 4 , the arithmetic mean was 3.00 , which meant that the competitors is at a medium level in terms of effort.

- Attention of judoka to the opponent's tactic - values ranged between 2 and 4 with an average value of 2.77 , which indicates a low to medium value, demonstrating low capacity of attention.

- Finalisation of actions - the values of athletes were between 2 and 4, the average value is 2.76 , which is low, and therefore appears that combative capacities should be carefully developed to best effect in the fight.

- Ending the fight by abandon - the values recorded in the observation sheet indicates the minimum 1 and maximum 4 and mean 2.66, a low showing a deficiency in terms of self-confidence, attention, and combativeness and explains many battle losses by forfeit.

- The influence of external factors during the completion on judoka - results between 1 and 4 with an average of 2.50, which also indicates that athletes are not sufficiently trained in terms of mental resistance to external environmental factors that might intimidate.

- The capacity of psychological and physical recover of judoka - values between 1 and 4 and an average value of 2.43, which indicates a deficiency in this respect.

- Decisional responsibility - recorded values between 1 and 4 with a mean of 2.43 , also a low value that demonstrates the lack of a training program in mental training.

- The following graph is showing the mean, the maximum value and the minimum value for each of the items in the protocol. 


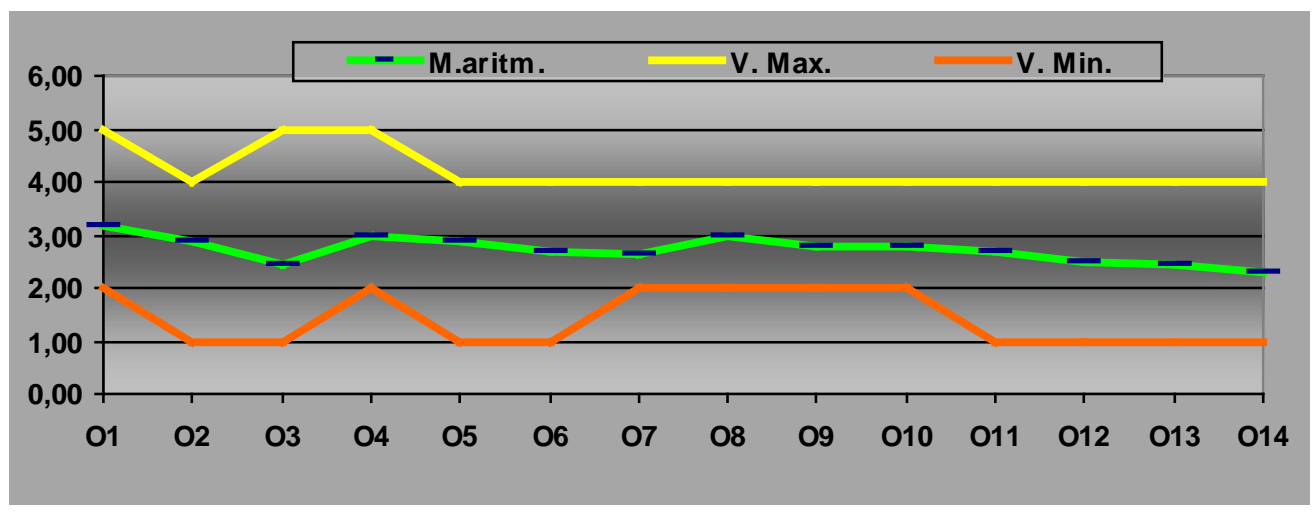

Figure 1. Interpretation of experimental data

\section{Discussions}

As we can see, the results of this study are favourable to our hypothesis. The scientific literature regarding attention and combativeness in judo is almost inexistent, therefore arises the need of more studies to be done in this area, so we can compare the results and draw more conclusions regarding this matter.

\section{Conclusions}

At the end of this study we can affirm that the hypothesis were confirmed. Following the analysis of data from the observation protocol we can conclude that for the group of athletes in the sample, the results are neither very low nor very high, that falls at a medium to low, which signifies that these athletes need an optimization strategy regarding improving their potential. This strategy, in the form of psychological training program should be appropriate, well-planned, so the results could climb to the upper limits.

Following application and interpretation of data from this observation protocol is clear the importance of attention and combativeness, and other psychological factors in the competition process, which are involved in every moment of training or combat.

\section{References}

1. ANGUS, R. (2006). Competitive Judo Winning training and tactics, U.S.A.: Human Kinetics;

2. BOMPA, T. O., \& HAFF, G. G. (2009). Periodization: Theory and Methodology of Trening, Leeds, UK: Human Kinetics;

3. DELIU, D. (2008). Antrenamentul sportiv în luptele de combat, București: Bren;

4. EPURAN, M., Holdevici, I., \& Tonița, F. (2008). Psihologia sportului de performanță: teorie și practică, București: Editura FEST;

5. GAGEA, A. (2007). Cercetări interdisciplinare în sportul de performanță, București: Editura Ministerului Internelor și Reformei Administrative; 
6. HANTĂU, L. (2005). Judo - instruire şi antrenament, Bucureşti: Editura Didactică şi Pedagogică;

7. POP, A., \& POP, M. N. (2007). Judo instruirea elevilor privind procedeele tehnice din KYU 5 pentru grupele de incepători, Craiova: Editura Universitaria;

8. VERZA, E., \& VERZA, F.E. (2000). Psihologia vârstelor, București: Editura Pro Humanitate.

\title{
Studiu Privind Importanța Atenției Și Combativității în Competiții la Sportivii J udoka de 11-13 Ani
}

\author{
Sava Mihai-Adrian ${ }^{1}$ \\ Panaitescu Ana-Maria² \\ 'Universitatea "Vasile Alecsandri" din Bacau, Calea Marasesti, 157, 600115, Romania \\ ${ }_{2}^{2}$ Şcoala Gimnazială nr. 22, Bacău, General Gusa, 3, 600234, Romania
}

Cuvinte cheie : judo, atenție, combativitate, performanţă

\begin{abstract}
Atenţia şi combativitatea sunt doi factori care pot influenţa performanţa sportivilor judoka. Pentru a demonstra importanța atenției și combativității în judo la competiții, am întocmit un protocol de observație denumit „Importanța atenției și combativității în competiții” aplicat în cadrul competiţiilor pe un eșantion de 30 de sportivi judoka cu vârste cuprinse între 11-13 ani. Prin dezvoltarea atenției, sportivii judoka sunt capabili să își mobilizeze oportun și eficient forțele, să-și dirijeze rațional comportamentul. El prezintă o viteză mărită a vitezei de reacție, se orientează mai bine pe saltea, procesele de percepție decurg mai rapid, sunt mai clare și mai active, are spirit de observaţie mărit, capacitatea de a sesiza cele mai neobișnuite și mai dificile situații din timpul luptei. Controlul sportivului asupra acțiunilor sale este cerebral și foarte precis, iar mișcările pe care le execută au o coordonare perfectă și sunt foarte precise. El are încredere în forțele proprii (Angus, 2006). El este capabil să se analizeze autocritic după fiecare meci și să tragă concluzii binevenite pentru meciurile care urmează.
\end{abstract}

\section{Introducere}

Filosofia judo-ului se reflectă în moto-ul „Jita Kyoei” adică „totul este ca o unitate". Valoarea tradiției și filosofiei judo-ului precum și beneficiile care emerg din ele sunt cruciale. Judoka trebuie să învețe să se respecte pe el însuși, corpul său, antrenorii (Gagea, 2007). Sportivii judoka nu trebuie să învețe să fie doar pregătiți din punct de vedere fizic, dar și în spirit, prin puterea de concentrare, dedicație. Deci, un rol important în judo îl are pregătirea psihică (Hantău, 2005).

Combativitatea este tendința de a lupta cu toată energia pentru realizarea scopului propus, de învingere a oponentului, a altor „bariere” (spațiu, timp, 
gravitație) sau a propriilor performanțe anterioare (Verza, 2000). Combativitatea capătă trăsăturile unei atitudini active și constructive, individul folosindu-și inteligența, iar comportamentul său fiind dublat de dârzenie, elan de luptă, spirit de sacrificiu (Epuran, 2008). În judo, fiind în același timp artă și sport, principiile sunt clare și promovează individul sub aspectele unei condiții fizice și mentale deosebite, disciplină maximă, stoicism, corectitudine, respect față de sine și societate (Bompa, 2009). Ca urmare combativitatea în judo este esențială, definitorie pentru sportivul judoka. Potrivit principiilor mentorului Jigoro Kano, agresivitatea nu își are locul (Deliu, 2008). Cu toate acestea există și situații rare de agresivitate comportamentală, dar sunt aspru sancționate, mergând până la eliminarea sportivului din viața sportivă (Pop, 2007).

\section{Material şi metode}

Scopul acestui studio a fost identificarea și evaluarea obiectivă a nivelului general al atenției și combativității, în vederea optimizării procesului de pregătire psihologică prin elaborarea unei strategii instrucționale şi a metodologiei ei, prin intermediul căreia se va prognoza dezvoltarea parametrilor psihologici ai sportivilor judoka adolescenți.

Având în vedere scopul cercetării noastre și expectanțele noastre am formulat următoarele ipoteze de lucru:

1. Atenţia, combativitatea şi viteza de reacţie sunt componente ale capacităţii psihice care favorizează /limitează performanţa sportivă la judo.

2. În procesul de pregătire a judocanilor concentrarea şi distributivitatea atenţiei, combativitatea şi viteza de reacţie sunt variabilele independente ale capacităţii psihice.

Studiul bibliografic a constat în studiul mai multor lucrări care conțin acest subiect, a unor autori români și străini. Metoda observaţiei pedagogice directe, aplicată în lucrarea noastră a fost orientată spre înregistrarea atentă şi sistematică a reacţiilor şi conduitelor sportivilor judoka de 11-13 ani, a aptitudinilor motrice şi psihomotrice, a aptitudinilor psihologice, urmărindu-se, totodată, şi caracteristicile comportamentale şi temperamentale ale adolescenților în procesul direct de perfecţionare sportivă.

Subiecții experimentați au fost 30 judoka din cadrul Club Royal Bacău.

Pentru a demonstra importanţa atenției și combativității în judo la competiţii, am întocmit un protocol de observație denumit „Importanța atenției și combativității în competiții" aplicat în cadrul concursului pe un eșantion de 30 de sportivi judoka cu vârste cuprinse între 11-13 ani (Tabel 1).

În realizarea acestui protocol am avut în vedere diferite faze ale concursului începând cu intrarea în sala de concurs și pe saltea, începerea concursului și trecerea treptată prin diferite faze ale unei lupte (luarea prizelor, intrarea la procedee, fixări, luxări, strangulări, finalizarea acțiunilor). Fiecare fază a fost observată din punctul de vedere al cercetării noastre și anume observarea componentelor atenției (distributivă, concentrată, viteză de reacție) și combativității implicate în aceste procese. 

Tabel 1. Protocolul de observaţie "Importanţa atenţiei şi combativităţii în timpul
competiţiilor"

\begin{tabular}{|c|c|c|c|}
\hline \multicolumn{4}{|c|}{ Importanța atenției și combativității în timpul competițiilor } \\
\hline \multicolumn{4}{|c|}{ 1.Concentrarea atenției în momentele premergătoare concursului } \\
\hline Maximă(5) $\quad$ Ridicată(4) & Medie(3) & Suficientă(2) & Insuficientă(1) \\
\hline \multicolumn{4}{|c|}{ 2.Gradul de eliminare a factorilor de distragere a atenției } \\
\hline F. bun(5) $\quad$ Bun(4) & Mediu(3) & $\operatorname{Slab}(2)$ & F. slab(1) \\
\hline \multicolumn{4}{|c|}{ 3. Starea psihică a sportivului înainte de concurs } \\
\hline F. $\operatorname{calm}(4)$ & Calm(3) & Agitat(2) & Nervos $(1)$ \\
\hline \multicolumn{4}{|c|}{ 4. Luarea prizelor adecvate la intrarea în procedeu } \\
\hline F. bun(5) $\quad$ Bun(4) & Mediu(3) & Slab(2) & F. slab(1) \\
\hline \multicolumn{4}{|c|}{ 5. Adaptarea sportivului la situația de luptă } \\
\hline F. bună(5) $\quad$ Bună(4) & Medie(3) & Slabă(2) & F. slabă(1) \\
\hline \multicolumn{4}{|c|}{ 6. Distribuția atenției pe diferiți factori ai unui moment al luptei } \\
\hline F. bună(5) $\quad$ Bună(4) & Medie(3) & Slabă(2) & F. slabă(1) \\
\hline \multicolumn{4}{|l|}{ 7. Inițiativa } \\
\hline Permanent(5) & Rareori(3) & Uneori(2) & Niciodată(1) \\
\hline \multicolumn{4}{|l|}{ 8. Angajarea în efort } \\
\hline Maximă(5) $\quad$ Ridicată(4) & Medie(3) & Slabă(2) & Foarte slabă(1) \\
\hline \multicolumn{4}{|c|}{ 9. Atenția sportivului la tactica adversarului și valorificarea momentului } \\
\hline F. bună(5) Bună(4) & Medie(3) & Slabă(2) & F. slabă(1) \\
\hline \multicolumn{4}{|l|}{ 10. Finalizarea acțiunilor } \\
\hline Permanent(5) Des(4) & Rareori(3) & Uneori(2) & Niciodată(1) \\
\hline \multicolumn{4}{|l|}{ 11. Terminarea luptei prin abandon } \\
\hline Niciodată(5) $\quad$ Rareori(4) & Uneori(3) & $\operatorname{Des}(2)$ & Permanent(1) \\
\hline \multicolumn{4}{|c|}{ 12. Influențarea stării sportivului în timpul concursului de către factorii externi } \\
\hline Niciodată(5) ～Rareori(4) & Uneori(3) & $\operatorname{Des}(2)$ & Permanent(1) \\
\hline \multicolumn{4}{|c|}{ 13. Capacitatea de refacere psihică și fizică a sportivului } \\
\hline Foarte ridicată(4) & Ridicată(3) & Medie(2) & Scăzută(1) \\
\hline \multicolumn{4}{|l|}{ 14. Responsabilitatea decizională } \\
\hline Foarte ridicată(4) & Ridicată(3) & Medie(2) & Scăzută(1) \\
\hline
\end{tabular}

Fiecare dintre itemii urmăriţi au fost măsurați pe o scală de la 1 la 5 unde 1valoarea minimă, 5 - valoarea maximă, iar pentru unii itemi de la 1 la 4,1 fiind valoarea minimă și 4 valoarea maximă.

\section{Rezultate şi discuţii}

Datele experimentale obținute în urma aplicării protocolului de observație sunt prezentate în tabelul 2. În urma observației desfășurată privind importanța atenției și combativității în competiții la judo, conform datelor centralizate prezentate în tabelul de mai sus, se desprind următoarele interpretări:

- Concentrarea atenției în momentele premergătoare concursului - încă de la intrarea în sala de concurs psihicul sportivului este expus unor factori care le pot distrage atenția de la obiectivele meciului. În urma observării acestui element, punctajele se regăsesc în intervalul 2-5, media aritmetică a valorilor fiind de 3,16.

- Din analiza acestor valori reiese faptul că, capacitatea de concentrare a 
Sava M.A., Panaitescu A.M. / Gymnasium

atenției în momentele premergătoare concursului, este destul de scăzută pentru eșantionul pe care l-am observat.

Tabel 2. Date experimentale obtinute ca urmare a aplicării protolului de observaţie

\begin{tabular}{|c|c|c|c|c|c|c|c|c|c|c|c|c|c|c|}
\hline $\begin{array}{l}\text { Nr. } \\
\text { crt }\end{array}$ & 01 & $\mathbf{O 2}$ & O3 & 04 & O5 & 06 & O7 & 08 & O9 & 010 & 011 & 012 & 013 & 014 \\
\hline S1 & 2 & 1 & 2 & 3 & 2 & 2 & 2 & 3 & 2 & 3 & 1 & 2 & 1 & 1 \\
\hline S2 & 3 & 3 & 2 & 3 & 3 & 3 & 2 & 3 & 3 & 2 & 2 & 2 & 2 & 2 \\
\hline S3 & 2 & 3 & 2 & 3 & 3 & 3 & 2 & 3 & 3 & 3 & 2 & 2 & 2 & 2 \\
\hline S4 & 4 & 3 & 3 & 3 & 4 & 4 & 3 & 4 & 3 & 4 & 3 & 3 & 2 & 3 \\
\hline S5 & 4 & 3 & 3 & 4 & 4 & 3 & 3 & 4 & 4 & 3 & 3 & 3 & 2 & 2 \\
\hline S6 & 2 & 2 & 3 & 2 & 3 & 3 & 3 & 2 & 3 & 3 & 3 & 2 & 2 & 2 \\
\hline S7 & 3 & 4 & 3 & 2 & 3 & 2 & 3 & 3 & 2 & 2 & 2 & 1 & 1 & $\overline{1}$ \\
\hline S8 & 3 & 4 & 3 & 4 & 4 & 3 & 2 & 3 & 3 & 3 & 4 & 3 & 3 & 2 \\
\hline S9 & 2 & 2 & 2 & 2 & 3 & 2 & 3 & 3 & 3 & 2 & 2 & 2 & 2 & 1 \\
\hline S1 & 3 & 3 & 2 & 3 & 2 & 3 & 3 & 3 & 2 & 2 & 3 & 3 & 2 & 2 \\
\hline S1 & 3 & 3 & 2 & 3 & 3 & 3 & 2 & 3 & 2 & 3 & 3 & 2 & 2 & 2 \\
\hline S1 & 4 & 3 & 3 & 3 & 4 & 4 & 3 & 4 & 3 & 3 & 3 & 4 & 3 & 3 \\
\hline S1 & 5 & 4 & 5 & 5 & 4 & 4 & 4 & 4 & 4 & 3 & 5 & 4 & 4 & 4 \\
\hline S1 & 2 & 3 & 4 & 3 & 3 & 3 & 2 & 3 & 3 & 3 & 3 & 2 & 3 & 3 \\
\hline S1 & 3 & 3 & 2 & 3 & 2 & 3 & 3 & 2 & 2 & 2 & 2 & 3 & 3 & 2 \\
\hline S1 & 3 & 3 & 2 & 4 & 3 & 3 & 3 & 3 & 2 & 3 & 2 & 2 & 3 & 2 \\
\hline S1 & 4 & 3 & 3 & 3 & 2 & 2 & 3 & 2 & 3 & 3 & 3 & 2 & 3 & 2 \\
\hline S1 & 2 & 2 & 2 & 2 & 3 & 2 & 2 & 3 & 4 & 3 & 3 & 3 & 2 & 2 \\
\hline S1 & 3 & 3 & 2 & 2 & 2 & 3 & 2 & 2 & 3 & 3 & 2 & 2 & 2 & 2 \\
\hline S2 & 3 & 3 & 2 & 3 & 3 & 2 & 3 & 3 & 3 & 3 & 3 & 2 & 2 & 3 \\
\hline S2 & 3 & 2 & 3 & 4 & 3 & 3 & 3 & 4 & 2 & 3 & 3 & 3 & 3 & 3 \\
\hline S2 & 3 & 1 & 2 & 2 & 3 & 1 & 2 & 3 & 3 & 2 & 3 & 3 & 2 & 2 \\
\hline S2 & 4 & 3 & 2 & 3 & 3 & 2 & 3 & 3 & 2 & 3 & 3 & 4 & 3 & 3 \\
\hline S2 & 4 & 3 & 2 & 3 & 3 & 3 & 4 & 4 & 3 & 3 & 3 & 3 & 2 & 3 \\
\hline S2 & 3 & 3 & 1 & 2 & 2 & 2 & 3 & 3 & 2 & 2 & 2 & 2 & 2 & 2 \\
\hline S2 & 5 & 4 & 4 & 3 & 3 & 3 & 2 & 2 & 3 & 3 & 3 & 3 & 3 & 3 \\
\hline S2 & 3 & 3 & 2 & 3 & 3 & 3 & 2 & 3 & 3 & 2 & 2 & 2 & 3 & 2 \\
\hline S2 & 4 & 3 & 3 & 4 & 3 & 4 & 3 & 3 & 4 & 3 & 3 & 3 & 3 & 3 \\
\hline S2 & 3 & 3 & 2 & 3 & 2 & 3 & 3 & 3 & 2 & 3 & 2 & 2 & 3 & 2 \\
\hline S3 & 3 & 3 & 1 & 2 & 1 & 2 & 2 & 2 & 2 & 2 & 2 & 1 & 2 & 1 \\
\hline $\mathbf{X}$ & 3.1 & 2.8 & 2.4 & 2.9 & 2.8 & 2.7 & 2.6 & 3.0 & 2.7 & 2.76 & 2.66 & 2.50 & 2.4 & 2. \\
\hline $\mathbf{S}$ & 0.83 & 0.73 & 0.86 & 0.76 & 0.73 & 0.87 & 0.61 & 0.64 & 0.67 & 0.5 & 0.7 & 0.7 & 0.62 & 0.65 \\
\hline Vmax & 5 & 4 & 5 & 5 & 4 & 4 & 4 & 4 & 4 & 4 & 4 & 4 & 4 & 4 \\
\hline V.min & 2 & 1 & 1 & 2 & 1 & 1 & 2 & 2 & 2 & 2 & 1 & 1 & 1 & 1 \\
\hline
\end{tabular}

- La eliminarea factorilor de distragere a atenției - observăm că valorile sunt cuprinse între 1 și 4 , media valorilor fiind 2,86. Aceste valori exprimă faptul că sportivii nu au o pregătire specială privind acest aspect, ei neputând face față întrun mod optim la factorii externi precum publicul, afișaje electronice, stres,etc., media aritmetică fiind situată în partea valorilor slabe.

- Pentru Starea psihică a sportivului înainte de concurs am observat că valoarea medie a rezultatelor este 2,46 minimul fiind 1 și maximul de 5. Și în acest caz am observat că starea generală a sportivilor înainte de începerea concursului nu era cea mai prielnică sportivii fiind caracterizați de agitație sau nervozitate vizibile, puțini fiind caracterizaţi de calm și echilibru.

- Luarea prizelor adecvate la intrarea în procedeu - acesta este un moment important de la începutul luptei în judo care pregătește terenul sportivului pentru 
aplicarea procedeelor. De aceea sportivul trebuie să fie atent la tactica adversarului, să aibă timpi de reacție foarte buni. În acest caz am constatat că valorile obținute au fost situate între 2 și 5 . Media aritmetică este de 2,97 de asemenea o valoare scăzută care demonstrează că din punctul de vedere urmărit în ceea ce privește calitățile atenției este o valoare deficitară.

- Adaptarea sportivului la situația de luptă - se observă că rezultatele sunt cuprinse între 1 și 4 , media valorilor fiind de 2, 87 de asemenea situată în zona rezultatelor slabe care demonstrează că sportivii au nevoie ca anumite componente ale atenției să fie mai dezvoltate astfel încât sportivul să crească și capacitatea de adaptare a acestuia.

- Distribuția atenției pe diferiți factori ai unui moment al luptei - și la acest aspect sportivii au înregistrat valori în zona inferioară și anume 2,70 valoarea minimă fiind 1 și maximă 4 .

- La inițiativă - se observă o valoare minimă de 2 și o valoare maximă de 4 , valoarea medie fiind de 2,63, de asemenea o valoare situată în zona de jos a valorilor, ceea ce scoate în evidență o combativitate scăzută în luptă, neîncrederea în forțele proprii, o viteză de reacție scăzută.

- Angajarea în efort - în acest caz valoarea minimă a fost de 2, iar valoarea maximă de 4 , media aritmetică a valorilor fiind 3,00 , de unde rezultă că sportivii se situează la un nivel mediu în ceea ce privește efortul.

- Atentia sportivului la tactica adversarului și valorificarea momentului - acest item este relevant pentru studiul nostru deoarece reflectă nevoia de o bună atenție distributivă și concentrată pentru a valorifica anumite elemente din timpul jocului adversarului pentru a-i contracara acțiunile, astfel încât să întoarcă meciul în favoarea sa. În acest caz valorile au oscilat între 2 și 4 valoarea medie fiind de 2,77 , ceea ce indică o valoare scăzută spre medie, demonstrând capacitatea redusă de atenție.

- Asumarea acțiunilor de finalizare - pentru aceasta sportivii au nevoie de asemenea de calități sporite de atenție și combativitate. Valorile înregistrate de sportivi au fost cuprinse între 2 și 4 , valoarea medie fiind de 2,76 , valoare situată în partea medie spre inferioară a valorilor, deci și din observarea acestui element reiese că, capacităţile de atenție și combativitate ar trebui dezvoltate pentru optimizarea acțiunilor din cadrul luptei.

- Terminarea luptei prin abandon - acest fapt de multe ori întâlnit în cadrul unei lupte, atunci când sportivul pierde prin abandon, înainte de terminarea regulamentară a meciului reflectă o rezistență fizică și psihică redusă. Sportivul care abandonează nu are încredere în forțele proprii, este intimidat de adversar, are viteză de reacție scăzută. Valorile înregistrate în fișa de observație indică valoarea minimă 1 și maximă 4 , iar valoarea medie 2,66 , o valoare scăzută care arată o deficiență în ceea ce privește încrederea în sine, în atenție, combativitate și explică numeroasele pierderi ale luptei prin abandon.

- Influențarea stării sportivului în timpul concursului de către factorii externi - şi în timpul concursului ca şi înaintea lui sportivii trebuie să își concentreze atenția asupra obiectivelor luptei şi trebuie să aibă puterea de a ignora factorii externi perturbatori. Observațiile acestui element ne indică rezultate cuprinse între 
1 și 4 cu o valoare medie de 2,50, care de asemenea ne indică faptul că sportivii nu sunt destul de antrenați din punctul de vedere al rezistenței psihice față de factorii mediului extern care ar putea să îi intimideze.

- Capacitatea de refacere psihică și fizică a sportivului - aceasta este un factor important în timpul unei lupte. Este important ca sportivul să cunoască cum să își revină și să se întoarcă la luptă în anumite momente dificile pe care le presupune aceasta. Pentru aceasta este nevoie de anumite tehnici speciale pe care sportivul să le cunoască și să le aplice. Pentru acest item al fișei de observație s-au înregistrat valori cuprinse între 1 și 4 și o valoare medie de 2,43 , ceea ce arată o deficiență în acest sens.

- Responsabilitatea decizională - sportivii trebuie să îşi asume responsabilitatea deciziilor sale. Aceasta presupune o personalitate puternică cu calităţi psihice dezvoltate. În cadrul observațiilor noastre la acest element sportivii au înregistrat valori cuprinse între 1 și 4 cu o valoare medie de 2,43, de asemenea o valoare slabă care demonstrează lipsa unui program de pregătire psihică în cadrul antrenamentelor.

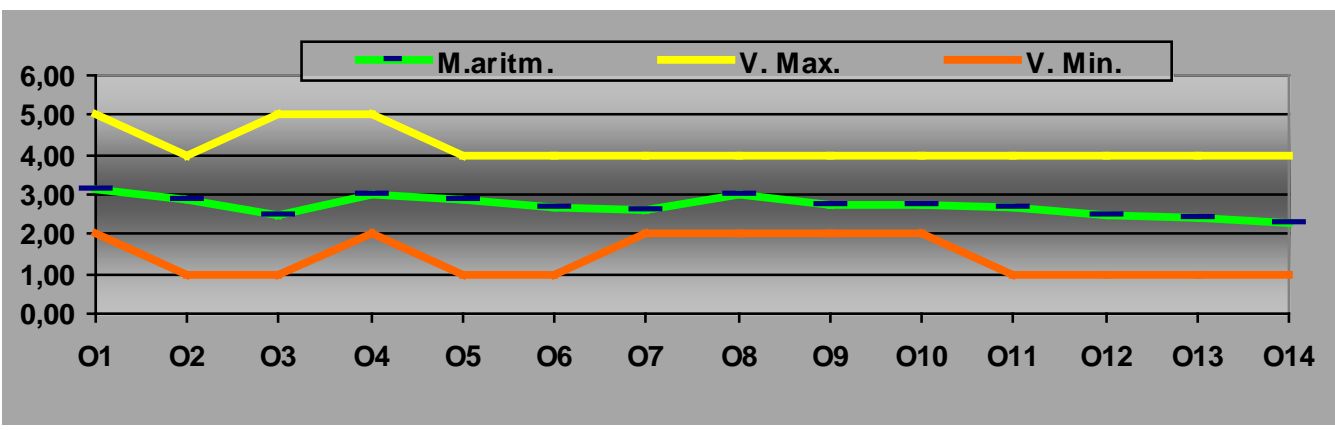

Figura 1. Interpretarea datelor experimentale

\section{Discuţii}

După cum se observă, rezultatele studiului de faţă sunt în favoarea ipotezei noastre. Literature ştiinţifică în domeniul atenţiei şi combativităţii în judo este aproape inexistentă şi prin urmare, apare nevoia de alte studii similar a fi realizate în acest domeniu de studio, astfel încât să putem compara rezultatele şi să extragem mai multe concluzii.

\section{Concluzii}

Ca urmare a analizei datelor obținute în protocoalele de observație putem să concluzionăm că la nivelul grupului de sportivi din eșantion, rezultatele obținute nu sunt nici foarte scăzute și nici foarte ridicate, adică se încadrează la un nivel mediu spre scăzut, ceea ce are semnificația că acești sportivi au potențial și că în urma unui program adecvat, bine planificat de optimizare a calităților psihice, rezultatele ar putea să urce la limita superioară.

Din acest protocol de observație reiese clar importanța atenției și combativității, precum și a altor factori psihici în procesul competițional, aceștia fiind implicați în fiecare moment al antrenamentului sau luptei. 